\title{
Lutas sociais contra a privatização da saúde na Espanha
}

\author{
Andréia Oliveira ${ }^{1}$ \\ https://orcid.org/0000-0001-8759-059X
}

\author{
Carlos Alvarez-Dardet Díaz ${ }^{3}$ \\ https://orcid.org/0000-0003-3530-7451
}

\author{
Jorge Marcos Marcos ${ }^{2}$ \\ https://orcid.org/0000-0002-7607-6672 \\ ${ }^{1}$ Universidade de Brasília, Departamento de Serviço Social, Programa de Pós-Graduação em Política Social, Brasília, DF, \\ Brasil \\ ${ }^{2}$ Universidad de Alicante, Departamento de Psicología de la Salud, Comunidad Valenciana, España \\ ${ }^{3}$ Universidad de Alicante, Departamento de Enfermería Comunitaria, Medicina Preventiva y Salud Pública e Historia de la \\ Ciencia, Alicante, Comunidad Valenciana, España
}

\section{Lutas sociais contra a privatização da saúde na Espanha}

Resumo: Neste estudo buscamos identificar as formas e estratégias de mobilização coletiva de contestação e protesto no enfrentamento das medidas neoliberais e de austeridade no Sistema Nacional de Saúde na Espanha, tomando como referência o Real Decreto-ley 16/2012 e o Real Decreto-ley 7/2018. O estudo se sustenta no uso de método qualitativo com instrumentos múltiplos de coleta, baseado em revisão narrativa da literatura, análise documental e aplicação de questionário com perguntas abertas a pessoas de referência na área, profissionais e líderes de associações, com posicionamentos contrários às restrições ao direito universal à saúde. Os resultados sugerem que as mobilizações e ações de protesto conseguiram deter as propostas do Real Decreto-ley 16/2012. Os êxitos são considerados inspiradores, mas não suficientes. A saúde passa a ser vinculada novamente à condição de cidadania, no entanto, há reminiscências do modelo anterior e permanecem as disputas com o setor privado. Palavras-chave: Participação social. Mobilização coletiva. Sistema Universal de Saúde. Neoliberalismo.

\section{Social Strugles Against Health Privatization in Spain}

Abstract: In this study we sought to identify the forms and strategies of collective mobilization of contestation and protest against neoliberal and austerity measures in National Health System in Spain, as referred in the Royal Decree-Law 16/2012 and the Royal Decree-Law 7/2018. This study is founded on qualitative method with multiple instruments of collection, based on bibliographical reviews, on documental analysis and the application of open-ended questionnaires with selected people in the area, and with professionals and association leaders contrary to the restrictions against universal health rights. The results suggest that the mobilizations and protest acts managed to detain the Royal Decree-Law 16/2012 and the Royal DecreeLaw 7/2018. The successes are considered inspiring, but not enough. Health becomes once more linked to the condition of citizenship, however, there are reminiscences of the previous model, and the disputes with the private sector remain.

Keywords: Social participation. Collective mobilization. Unified Health System. Neoliberalism.

Recebido em 12.11.2020. Aprovado em 15.12.2020. Revisado em 13.02.2021.

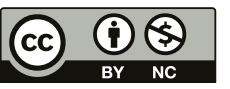

Este é um artigo publicado em acesso aberto (Open Access) sob a licença Creative Commons Attribution NonCommercial, que permite uso, distribuição e reprodução em qualquer meio, sem restrições desde que sem fins comerciais e que o trabalho original seja corretamente citado. 


\section{Introdução}

A introdução de sistemas nacionais de saúde universais constituiu fenômeno marcante nos países capitalistas europeus durante o século XX, sobretudo no período pós-Segunda Guerra Mundial, com a expansão do padrão de proteção social nos Estados de Bem-Estar Social (Welfare States) (ESPING-ANDERSEN, 1991). Ao final do século XX, após a caída do muro e da implosão do bloco soviético e início do século XXI, novas configurações do capitalismo repercutem diretamente nos modelos de proteção social, empreendidas segundo análises, em decorrência do fortalecimento do neoliberalismo e do conservadorismo, com deslocamento da proteção social dos campos público e estatal para a mercantilização, ou seja, "a proteção social naturalizada e extraída de seu valor de direito humano e civilizatório é transformada em mercadoria, cujo valor agregado e estratégico é direcionado a interesses que comprometem sua finalidade protetiva, e ampliam as desigualdades sociais". (SPOSATI, 2018, p. 2316).

Nesse contexto, países da União Europeia, entre os quais, a Espanha, têm se defrontado, em especial nas duas primeiras décadas do século XXI, com pressões financeiras acentuadas em seus sistemas universais de saúde, notadamente na conjuntura das respostas governamentais à crise econômica mundial de 2008, com redução da intervenção estatal, ampliação do poder do setor privado e das forças do mercado e reforço da financeirização da economia. (CORDILHA; LAVINAS, 2018; SERAPIONI, 2017). A universalidade dos sistemas nacionais de saúde é questionada e ameaçada frente às seguintes estratégias de acumulação de capital: 1) expansão de mecanismos gerencias privatistas; 2) novas modelagens na relação entre setor público x privado na provisão dos serviços de saúde; 3) ampliação da competição entre as entidades seguradoras nos seguros sociais; 4) aumento da participação de usuários nas despesas por meio de copagamento (GIOVANELLA; STEGMÜLLER, 2014); e 5) concentração de tendências de privatização, mercantilização e desigualdades em saúde (SERAPIONI, 2017).

Na Espanha, a Ley General de Sanidad, de 1986 (ESPAÑA, 1986), instituiu o Sistema Nacional de Salud (SNS) e intensificou o processo de transferência das competências sanitárias para as 17 Comunidades Autônomas (CCAA) do país. Esse processo de reforma contribuiu na efetivação do direito à saúde e na melhora significativa da qualidade dos serviços, com bons resultados e alta aceitação (BERNAL-DELGADO et al., 2018), apesar de não ter extinguido as desigualdades geográficas no acesso aos serviços de saúde e no seu uso. (BORGES; LÓPEZ-FERNÁNDEZ; CAMPOS, 2018).

As crises de final da primeira década do século XXI, apontadas, de modo retórico, como motivo da implantação de medidas de austeridade, têm produzido uma contrarreforma sanitária na Espanha mediante iniciativas de privatização dos serviços e de hegemonização do setor privado, ocasionando deterioração do sistema de saúde. (SÁNCHEZ BAYLE; RUIZ, 2014; BORGES; LÓPEZ-FERNÁNDEZ; CAMPOS, 2018; PADILLA, 2019). Expressão significativa dessa contrarreforma no sistema de saúde espanhol se deu por meio do Real Decreto-ley 16/2012 (ESPAÑA, 2012), com o qual foram alteradas as bases fundantes do modelo de universalidade do sistema de saúde, introduzindo uma lógica restritiva e asseguramento (SÁNCHEZ BAYLE; RUIZ, 2014). A resposta social e profissional constituiu um amplo movimento de resistência e contestação a tal normativa legal, resultando na revogação do Real Decreto-ley 16/2012 (ESPAÑA, 2012), com a promulgação de uma nova legislação, Real Decreto-ley 7/2018 (ESPAÑA, 2018), em que se vinculava novamente a saúde a uma condição de direito de cidadania.

Estamos diante de um tema recorrente nas agendas acadêmicas, governamentais e dos movimentos sociais. O debate em torno do direito universal à saúde, em 2020, ganhou magnitude em escala mundial com a pandemia do novo SARS-CoV-2. O conflito já existente ganha visibilidade frente à ameaça de falta de capacidade de atendimento dos sistemas de saúde, gerando questionamentos sobre a priorização da saúde como um direito social. Nesse sentido, os autores do presente estudo concordam com Javier Padilla (2019), em seu livro “¿A quién vamos a dejar morir?”, pois a abordagem da saúde como bem social exige que a sociedade se transforme para dar respostas coletivas e de resistência à mercantilização do sistema e da vida em geral.

O propósito deste estudo é contribuir na construção de estratégias coletivas de consolidação da saúde como direito social e responsabilidade do Estado. Isso significa destacar a relevância da reação e organização da sociedade no enfrentamento da perda de direitos, e da sobreposição dos interesses do setor privado e do mercado. 
Nesse sentido, partimos do entendimento de que os movimentos coletivos de contestação e protesto têm capacidade de revitalizar as estratégias de luta e de resistência dos mecanismos de subordinação social e, no âmbito da saúde, de contribuir na expansão das bases políticas e sociais da luta pelo direito social à saúde. Buscou-se identificar, nesta investigação, formas e estratégias de mobilização coletiva de contestação e protesto, no enfrentamento das medidas neoliberais e de austeridade no Sistema Nacional de Saúde na Espanha, tomando como referência o Real Decreto-ley 16/2012 e a retomada da concepção de universalidade do Sistema Nacional de Saúde, por meio do Real Decreto-ley 7/2018.

\section{Metodologia}

Este estudo exploratório, de natureza qualitativa, foi composto por três fases complementares: revisão narrativa da literatura sobre a temática; análise documental do marco legal-normativo; e aplicação de questionário com perguntas aberta a pessoas (informantes-chave) de referência na área, profissionais e/ou líderes de associações que se posicionaram contrários às restrições ao direito universal à saúde na Espanha.

Fase 1 - Revisão preliminar da literatura referente ao estado da arte da resposta popular e profissional perante a configuração da política de saúde na Espanha, no período 2012-2020. A revisão foi realizada por meio de busca na Biblioteca Virtual de Saúde (BVS) e nas bases de dados Scopus e SciELO, mediante o emprego de distintas combinações das palavras-chave: sistema de saúde, participação da comunidade, protesto, neoliberalismo, austeridade, Espanha, nos idiomas português, inglês e Espanhol. Como critério geral de inclusão, foram selecionados estudos com a seguinte abordagem: configuração da política de Saúde na Espanha desde 2012 em relação ao modelo assistencial; desenvolvimento das medidas recessivas no âmbito do SNS, especialmente por meio do Real Decreto-ley 16/2012; e reações e estratégias adotadas pela população afetada por tais medidas.

Fase 2 - Análise documental do Real Decreto-ley 16/2012, de 24 de abril de 2012 (ESPAÑA, 2012) e seus posteriores desdobramentos normativos, os quais originaram uma onda de protestos e manifestações dos movimentos sociais contra tais medidas, consideradas como características de um processo de desmantelamento da universalidade do direito universal a saúde.

Fase 3 - Aplicação de questionário de nove perguntas abertas a informantes-chave de associações/ entidades profissionais e organizações da sociedade civil (coletivos e plataformas cidadãs), com presença e participação ativa em mobilizações e protestos sociais, em oposição as medidas adotadas no sistema de saúde pública na Espanha com a promulgação do Real Decreto-ley 16/2012, posteriormente revogado pelo Real Decreto-ley 7/2018, no qual foi retomada a perspectiva da universalidade do Sistema Nacional de Saúde (ESPAÑA, 2018). Na primeira parte do questionário foi abordada a opinião de tais informantes-chave no tocante ao contexto sanitário na Espanha, no momento da promulgação do Real Decreto-ley 16/2012. A segunda parte foi focalizada na resposta popular e profissional com respeito às medidas adotadas em termos da base desta norma jurídica. A participação foi voluntária; os respondentes receberam informações completas a respeito do objetivo do estudo, instituições envolvidas, compromisso dos pesquisadores em proteger a confidencialidade e anonimato das informações prestadas, além de utilizar o material coletado com finalidade exclusiva de investigação científica. Todos os consultados assinaram termo de consentimento, de acordo com a legislação espanhola vigente (Ley Orgánica 15/1999, de 13 de dezembro). (ESPAÑA, 2015).

A interpretação dos dados se realizou seguindo os preceitos da análise de modalidade temática (MINAYO, 2010). No primeiro momento foi elaborada a leitura geral das respostas dos questionários; a seguir, foram identificados temas emergentes; e então foram estabelecidas as dimensões interpretativas e analíticas, em cruzamento com a revisão da literatura.

Concretamente, neste manuscrito foram tratados dois temas emergentes, evidenciados nos resultados na pesquisa: a) Neoliberalismo, austeridade e suas expressões no sistema de saúde na Espanha. b) Mobilização coletiva de contestação e protesto frente às medidas neoliberais austeras, com ênfase nas formas e estratégias de ação; principais demandas dos movimentos de contestação; participantes e organizadores; influência e efeitos na agenda da política pública de saúde. 


\section{Investidas de Privatização do Sistema Nacional de Saúde espanhol}

A Constituição Espanhola, de 1978, e a "Ley General de Sanidad", de 1986, instituíram os marcos legais de um Sistema Nacional de Saúde (SNS), do tipo beveridgiano, fundamentado nos princípios da universalidade, integralidade e descentralizado (GIOVANELLA; STEGMÜLLER, 2014; PADILLA, 2019). O processo de transição em direção a um sistema de saúde universal envolveu uma reforma financeira, na qual o antigo sistema, estruturado em seguros, foi transformado em um novo sistema financiado por impostos, sendo a "Ley de Presupuestos Generales del Estado", de 1999, outro marco de instituição da saúde como direito de cidadania. (PADILLA, 2019). A reforma ganhou concretude, progressivamente, e em 2002, a responsabilidade pela atenção à saúde foi plenamente transferida ao âmbito das 17 Comunidades Autônomas, com descentralização e autonomia político-administrativa (DURÁN; LARA; VAN WAVEREN, 2006). O financiamento passou a integrar as transferências gerais da União, sem vinculação, calculadas com base em critérios demográficos e serviços públicos a serem cobertos (GIOVANELLA; STEGMÜLLER, 2014).

Os fundos públicos representam mais de $71,1 \%$ do total de financiamento sanitário, procedem dos impostos gerais do Estado. Entretanto, as CCAA são responsáveis pela gestão da maior parte dos recursos públicos (BERNAL-DELGADO et al., 2018).

No ano de 2012, em contexto de crise, o governo conservador (Partido Popular - PP) promulgou, sob a retórica política da necessidade de implementar medidas de garantia da sustentabilidade do SNS, o Real Decreto-ley 16/2012, introduzindo o que se pode chamar de uma contrarreforma sanitária, trazendo inflexões no modelo sanitário, tornando-o mais restritivo, vinculando o direito à atenção à saúde ao modelo de asseguramento/ seguro. Dessa maneira, o Real Decreto-ley 16/2012, ao recuperar a condição de asseguramento/seguro, rompe com a perspectiva de cidadania sanitária e retorna às origens de um sistema de saúde de tipo bismarckiano (GIOVANELLA; STEGMÜLLER, 2014).

Estudos teóricos e investigações empíricas prévias (RUIZ; SÁNCHEZ BAYLE, 2016; GIOVANELLA; STEGMÜLLER, 2014) sugerem a utilização da crise como pretexto de introdução de reformas estruturais, sob a alegação de melhoria da eficiência e sustentabilidade financeira do sistema de saúde, porém com outros interesses presentes, especialmente com a promulgação do Real Decreto-ley 16/2012. De acordo com os informantes-chave, o principal interesse do governo na mudança do sistema de saúde, por meio do Real Decreto-ley 16/2012, centraram-se na retirada de direitos com o propósito de alavancar o setor privado, incentivar a privatização e implantar um sistema de saúde baseado em seguro. Os recortes a seguir retratam essas observações:

[...] ]obedecía a una oportunidad para recortar derechos por parte de un gobierno conservador con claras políticas neoliberales, que en otro contexto posiblemente no hubiese adoptado por el coste político que la medida tiene a nivel social. (R1)

El interés era hacer un Sistema Sanitario basados en Seguros [...]. (R3)

O processo é marcado pela falta de diálogo com a sociedade e com os trabalhadores, pois estes não opinam quanto à mudança legal de modelo universal para asseguramento. Os argumentos apresentados pelo governo para justificar tais medidas são frágeis e insuficientes; essas questões são analisadas em estudos teóricos do tema (SÁNCHEZ BAYLE; RUIZ, 2014; SUESS et al., 2014), e também elencadas pelos respondentes do questionário. O recorte a seguir elucida tal observação:

El Gobierno alegó que el sistema se encontraba al borde del colapso y con este único argumento, sin aportar memorias económicas que justificaran las medidas adoptadas. [...] Esta reforma se adoptó de espaldas a la sociedad, haciendo uso de una vía legislativa sin contar con la opinión del sector profesional ni consultar a las principales organizaciones sociales. (R5)

As análises teóricas realizadas por Padilla (2019), Sánchez-Bayle e Ruiz (2014) e Suess et al. (2014) são coincidentes com a posição dos sujeitos de pesquisa, ao considerarem o Real Decreto-ley 16/2012 
representativo de um retrocesso, em um sistema público de saúde pautado na perspectiva da universalidade e do direito de cidadania.

Do mesmo modo, no entendimento dos informantes-chave consultados, as mudanças atingiram a prestação equitativa na atenção à saúde, prejudicando principalmente as populações mais vulneráveis, com destaque dos segmentos de imigrantes e idosos, como se aprecia no seguinte extrato:

Los resultados han sido especialmente graves en el colectivo de inmigrantes no regularizados (hay al menos dos muertes documentadas) y se desconoce el número real de personas que han visto agravada seriamente su salud. El número de personas con problemas por estancias prolongadas en el exterior (básicamente en busca de trabajo) no se conoce. (R2)

A transformação do modelo sanitário em condição de asseguramento implicou em revisão da carteira de serviços: esta passou a ser fracionada em básica, complementar e suplementar (a primeira como gratuita; nas outras duas, estabeleceu-se o copagamento). Ocorreu ampliação de copagamento, como os serviços farmacêuticos e complementares (órteses, próteses). Além disso, a mudança resultou em consequências diretas a determinados segmentos populacionais, com destaque de imigrantes não documentados, estrangeiros com permanência temporária na Espanha, pessoas com moradia superior a 90 dias fora da Espanha, dentre outros. (SÁNCHEZ BAYLE; RUIZ, 2014; PADILLA, 2019; LÓPEZ-FERNÁNDEZ et al., 2012).

O contexto macroeconômico, no período entre 2009 a 2015, foi marcado pela recessão econômica, com diminuição de $20 \%$ do Produto Interno Bruto (PIB) per capita (BERNAL-DELGADO et al., 2018). Nesse mesmo período, o gasto público com saúde diminuiu em 0,9 pontos do PIB, o equivalente a uma redução de $5,3 \%$, ou seja, de 68.870 milhões de euros em 2009 a 65.199 milhões de euros em 2015. Entretanto, houve crescimento dos gastos privados com saúde, atingindo $28,9 \%$ do gasto total com saúde no mesmo período. O pagamento custeado diretamente pelos cidadãos representou 23,9\% da despesa total em saúde, em 2015, acima de $16,7 \%$ da média da União Europeia (EU). (BERNAL-DELGADO et al., 2018). Tais pagamentos devem-se, principalmente, aos copagamentos de medicamentos e à prestação de assistência médica, com repercussões na redução de gastos públicos no atendimento a essas necessidades de saúde (BERNAL-DELGADO et al., 2018). Análises referidas ao impacto da crise no sistema de saúde na Espanha são encontradas nos estudos de Rico e Blakey (2012), Bernal-Delgado et al. (2018) e Giovanella e Stegmüller (2014).

Os cortes foram menos impactantes sob o ponto de vista financeiro, porém os efeitos das mudanças representaram características ideológicas significativas. No tocante à concepção de modelo, a mudança consistiu em cortes financeiros na atenção primária $(5,7 \%)$ e na vigilância em saúde (35\%) sem, contudo, alterar o financiamento da assistência especializada (BORGES; LÓPEZ-FERNÁNDEZ; CAMPOS, 2018). Em termos de um projeto ético-jurídico, houve incorporação de elementos discriminatórios no estabelecimento de níveis de cidadania, pois a uns foi reconhecido o direito à saúde, e a outros não, desencadeando a expulsão de segmentos populacionais do sistema, especialmente da população migrante considerada em situação irregular (indocumentada).

As falas dos sujeitos da pesquisa aportam reflexões relativas ao fomento ao caráter xenofóbico, como expresso no seguinte extrato:

Los mensajes demagógicos con un trasfondo xenófobo se propagaron como la pólvora. [...]Llegué a tener en la mano un documento emitido por la Gerencia de Atención Primaria del Servicio de Salud de Castilla-La Mancha que amenazaba con abrir un expediente disciplinario a un médico por haber atendido a una persona en situación de irregularidad administrativa. (R5)

Apesar do caráter autoritário das medidas governamentais, não somente na propositura normativa, mas também na restrição da autonomia dos profissionais na forma de operar a atenção em saúde (SUESS et al., 2014), atitudes de resistência por parte dos profissionais da área se fizeram presentes. O extrato da fala de um dos respondentes do questionário, a seguir, reforça essa compreensão.

Muchas profesionales, sin embargo, continuaron ofreciendo atención a esta población (inmigrantes indocumentados), aunque no podían suministrarles algunas prestaciones básicas como medicación. (R1) 
O período analisado também foi caracterizado pela precarização das condições de trabalho e privatização dos serviços. A primeira se expressa em cortes com pessoal, por meio de: a) redução e congelamento dos salários; b) não substituição dos profissionais; e c) aumento jornada de trabalho. Por sua parte, a privatização dos serviços aparece de forma diferente entre as Comunidades Autônomas, configurada, essencialmente, nas novas formas de gestão de estabelecimentos públicos, parcerias público-privadas de concessão de serviços, cortes de recursos e aumento de copagamento (assistência farmacêutica em especial). (GIOVANELLA; STEGMÜLLER, 2014). A ênfase dos mecanismos de privatização dos serviços recaiu nos formatos de concessões administrativas, iniciativas de Financiamento Privado, Entidades de Base Associativas (EBAs), contratos e subcontratações. Esse processo privatizador ocasionou aumento de custos, sem melhoria equivalente na eficiência do sistema sanitário. Tal conjunto de situações desencadeou uma ampla mobilização social e profissional em contraposição às privatizações (SÁNCHEZ BAYLE; RUIZ, 2014).

No entanto, as CCAA responderam de maneira diferente aos cortes nos investimentos públicos e à aplicação do Real Decreto-ley 16/2012. Algumas delas, dependendo da perspectiva política dos governos regionais, seguiram atendendo os imigrantes em situação irregular; dentre estas CCAA, cinco interpuseram um recurso de inconstitucionalidade contra esta legislação. Este aspecto foi destacado em estudos relacionados ao tema (GIOVANELLA; STEGMÜLLER, 2014; RICO; BLAKEY, 2012; RUIZ; SÁNCHEZ BAYLE, 2016), e também foi assunto de manifestação de algumas pessoas consultadas na presente pesquisa. O seguinte extrato é um exemplo incidente nessa ideia:

Por suerte en Andalucía nos movilizamos inmediatamente a través de la Asociación para la Defensa de la Sanidad Pública (ADSP), no existía todavía las Mareas Blancas. Por suerte el gobierno andaluz no aceptó este RD [Real Decreto] y no se notó, aunque hubo problemas de trabajadores del sistema que no sabían esta decisión y les pasaban facturas, sobre todo a migrantes. (R3)

\section{A mobilização social e profissional no enfrentamento da contrarreforma sanitária espanhola}

A crise econômica mundial de 2008 colocou em evidência as desigualdades sociais do século XXI, em um momento histórico de esgotamento dos recursos naturais, emergência climática e ambiental, destacando a marca predatória do capitalismo. Tal momento coincide com profundos retrocessos democráticos e de direitos, ao mesmo tempo em que apresenta novos arranjos na esfera dos movimentos sociais e ações coletivas, motivados, em grande medida, pela falta de confiança dos cidadãos nas instituições políticas e na sua capacidade de resposta aos problemas coletivos agravados pelas crises (MATOS; SABARIEGO, 2020).

$\mathrm{Na}$ Espanha, o período foi marcado pelas tensões capitalistas em torno do Estado de bem-estar, representado no país pelas medidas de austeridade impostas pela Troika. (MATOS; SABARIEGO, 2020). Em tal contexto, emergem as mobilizações cidadãs de 15 de maio de 2011, posteriormente denominadas Movimento $15 \mathrm{M}$, movimento dos indignados, como uma reação contra a política econômica e as medidas austeras nas áreas sociais, como também de contestação à falta de autonomia da classe política espanhola (MATOS; SABARIEGO, 2020).

Nesse mesmo período, ações de protesto foram desencadeadas em diferentes setores. Na área da saúde, motivadas pelas ações do governo central — o qual influía diretamente no SNS e no incremento do processo privatizador, de modo especial com a publicação do Real Decreto-ley 16/2012 — um amplo movimento popular e profissional se mobilizou no enfrentamento a tais medidas, com sucessivos protestos, envolvendo diferentes segmentos organizados da sociedade, dos profissionais de saúde e sendo o mais conhecido, as "Mareas Blancas" (BORGES; LÓPEZ-FERNÁNDEZ; CAMPOS, 2018; SUESS et al., 2014).

Contudo, cabe ressaltar a ocorrência de incursões privatizadoras anteriores ao século XXI, no sistema de saúde, mesmo que de forma mais sutil, sem, contudo, deixar de tensionar e estabelecer campos de disputa e tensões com segmentos organizados da população, defensores da saúde como política pública e dever do Estado, como descrevem Sánchez Bayle e Ruiz (2014), ao retratarem as mobilizações sociais e profissionais em Galícia, Catalunha e Madrid em contraposição à contrarreforma sanitária na Espanha. Em Galícia as mobilizações ocorreram por ocasião da proposta de implantação das fundações sanitárias e da fundação da empresa MEDTEC (Instituto Gallego de Medicina Técnica), denominadas de "SOS Sanidad Pública". Em 
Cataluña, após as eleições, profissionais de saúde se mobilizaram contra os cortes no financiamento da saúde cujos efeitos resultaram no fechamento de centros de saúde, aumento na lista de espera e abandono na construção de hospitais. Em 2012 esse movimento perdeu densidade, sendo retomado no ano seguinte com forte presença dos sindicatos e entidades de profissionais e de segmentos cidadãos (SÁNCHEZ BAYLE; RUIZ, 2014).

Dessas lutas nascem as Plataformas em Defesa da Saúde Pública, compostas por entidades que agrupam forças políticas, sociais, comunitárias e profissionais.

Com a chegada do Partido Popular (PP) ao governo central, o movimento das Plataformas se estendeu por todo o País, com vida irregular e características distintas entre as CCAA, com destaque na defesa de financiamento público para garantir acesso a medicamentos, oposição à transformação de hospitais públicos em fundações e manifestações contrárias a outras medidas privativas. (SÁNCHEZ-BAYLE; RUIZ, 2014). Os protestos denominados "Mareas Blancas" (por causa dos jalecos dos médicos), na comunidade de Madri, constituíram outro marco expressivo nas ações de protesto, com convocações subsequentes em caráter nacional, no contexto do Real Decreto-ley 16/2012, ocorrendo sucessivas ondas de protestos no período 2012-2015. (BORGES; LÓPEZ-FERNÁNDEZ; CAMPOS, 2018).

As ações de protesto adquiriram organicidade, em âmbito nacional, em contraposição ao Real Decretoley 16/2012 e sua proposta de mudança do modelo sanitário público, vinculado à perspectiva de mudança do sistema fundamentado na saúde como direito (Ley General de Sanidad de 1986 e Ley General de Salud Pública, 2011) em sistema de asseguramento, no qual o acesso sanitário se regula por meio da condição de assegurado e beneficiário, aumento de copagamento e redução da carteira de serviços do Sistema Nacional de Saúde. Houve também protestos em defesa de uma das parcelas da população mais penalizadas pela perda da universalidade, ou seja, os imigrantes não documentados, como explicitado no estudo de Borges, LópezFernández e Campos (2018).

As mobilizações incluíram um conjunto de organizações da sociedade, associações profissionais, sindicatos profissionais e de classe, (Comisiones Obreras - CCOO; Unión General de Trabajadores - UGT), assim como a Federação de Associação para a Defesa da Sanidade Pública, uma plataforma de articulação de forças políticas, sociais, comunitárias e profissionais, em defesa do sistema público de saúde.

O movimento contou com manifestação de rua, abaixo-assinados, paralisações, desobediência civil, ocupações de centros de saúde, vigílias, consulta popular, ações cidadãs das mais variadas em defesa dos serviços públicos de saúde, sem deixar de mencionar o papel da Justiça e do Parlamento (SÁNCHEZ BAYLE; RUIZ, 2014). Embora tenham ocorrido em toda a Espanha, as Mareas Blancas foram muito ativas em Madri. Atingindo grande interesse social, elas alcançaram ampla repercussão das mídias, por meio da imprensa, rádio e televisão, oportunizando amplo debate sobre a relevância de um sistema de saúde universal e público (SÁNCHEZ BAYLE; RUIZ, 2014; BORGES, LÓPEZ-FERNÁNDEZ; CAMPOS, 2018).

As manifestações demonstraram apreço dos cidadãos e dos profissionais ao SNS e conseguiram deter as propostas do Real Decreto-ley 16/2012, com recuos decisivos nas iniciativas de privatização do setor, embora tenha sido mantida a transição ao modelo de asseguramento (BORGES, LÓPEZ-FERNANDEZ; CAMPOS, 2018; SUESS et al., 2014).

Como elementos facilitadores das manifestações de contestação no período, os informantes-chave destacaram: articulação dos setores dos trabalhadores da saúde com a população; a perda do direito à saúde afetaria grande parte da população, e não um grupo específico; facilidade na circulação da informação com grupos populacionais em situação de vulnerabilidade social, devido à legitimidade das entidades e associações protagonizadoras das manifestações; consciência social como motivadora das ações coletivas de protesto; as ações organizadas pelos afetados diretamente pelas medidas obtiveram maior êxito. Por outro lado, ressaltaram como principal dificuldade o fato de os meios de comunicação, situados no centro-direita ou na extrema direita, incentivarem o individualismo e promoverem um discurso contrário às manifestações e movimentos de protesto e de resistência. Além disso, o fato dos organizadores das manifestações (ou seus principais líderes) estarem vinculados a grupos e partidos de esquerda, fez com que alguns indivíduos deixassem de participar, apesar de concordarem com as reivindicações. Quanto aos partidos de esquerda, por outro lado, não conseguiram manter a unidade e a liderança indispensáveis ao avanço nas propostas.

A "Ley Orgánica de Protección de la Seguridad Ciudadana" (conhecida como «ley mordaza») (ESPAÑA, 2015) foi considerada, por um dos informantes-chave, como uma das dificuldades do movimento, assim como uma forma de repressão: 
En los primeros momentos del gobierno del Partido Popular la promulgación de la ley mordaza intimidó a los manifestantes por el uso de la imposición de multa de carácter administrativo [...]. Todo conjunto represor jugó seguramente un papel importante en dificultar los movimientos sociales. Sin duda, hay suficientes documentos gráficos de la violencia policial y de las detenciones arbitrarias usando la ley mordaza para no sólo, contener manifestaciones, sino también para impedir que colectivos sociales impidieran desahucios judiciales de personas que se quedaban sin hogar. (R4)

Entretanto, no entender os demais sujeitos da pesquisa, a intervenção da força pública era escassa e não provocou enfrentamentos com a polícia. Este fato também foi observado em estudos anteriores, nos quais constam reduzidas referências às respostas repressivas do Estado em tais manifestações (SÁNCHEZ BAYLE; RUIZ, 2014; BORGES, LÓPEZ-FERNANDEZ; CAMPOS, 2018; SUESS et al., 2014).

Com relação às conquistas alcançadas com a mobilizações e protestos sanitários no período, os sujeitos da pesquisa ressaltaram: visibilidades e recuperação da hegemonia social e profissional na defesa do direito universal à saúde; revogação do Real Decreto-ley 16/2012 e restituição do direito a grande parte da população residente no país, com a promulgação do Real Decreto-ley 7/2018 (ESPAÑA, 2018); interrupção da privatização em alguns serviços; denúncia dos prejuízos com relação às normativas impostas por organizações europeias; contribuição na mudança política nos governos regionais e central. Entretanto, observam que a legislação em defesa do direito à saúde foi restituída em caráter parcial, devido às seguintes ocorrências: os governos regionais e central passaram a adotar medidas de privatização mais gradual e silenciosa no setor saúde; a defesa do Sistema Nacional de Saúde tem se restringido ao acesso a determinadas tecnologias e serviços de atenção restritos à redução mínima de danos; e não vem sendo contemplada uma perspectiva mais ampla e completa do direito à saúde.

Conforme sugere a literatura relativa ao tema, as mobilizações e ações de protesto conseguiram deter os retrocessos empreendidos pelas propostas do Real Decreto-ley 16/2012, com ênfase no amplo apoio popular e profissional contra a privatização e em defesa do modelo de sistema universal de saúde (SÁNCHEZ BAYLE; RUIZ, 2014).

Nessa direção, Borges, López-Fernandez e Campos (2018), destacam o expressivo compromisso assumido pelos partidos políticos, em seus programas de governo nas eleições gerais de 2015 (com exceção do "PP y Ciudadanos"), junto às Associações Cidadãs, a fim de promover o direito universal à saúde.

Em 2018, em governo sob comando do "Partido Socialista Obrero Español (PSOE)", foi retomada a concepção da universalidade do Sistema Nacional de Saúde, por intermédio de uma nova legislação, o Real Decreto-ley 7/2018 (ESPAÑA, 2018). Entretanto, na avaliação de estudiosos como Padilla (2019), há reminiscências do modelo anterior, na medida em que, apesar da retomada da prerrogativa de universalidade, foram excluídos do acesso ao sistema segmentos populacionais, como familiares reagrupados, e residentes no país há menos de 90 dias, além da introdução de um regime mutualista especial, voltado a um grupo seleto de pessoas, incluindo juízes e militares.

Desse modo, apesar do reconhecimento do êxito das mobilizações de protestos, representadas especialmente pela Mareas Blancas, de acordo com análises dos informantes-chave, há que renovar, continuadamente, as formas de resistência e lutas para além do setor saúde, como expresso no extrato abaixo:

Hay que ser conscientes de que defender la Sanidad Pública choca con la corriente de modo de vida insolidario e individualista y el neoliberalismo preponderante y por eso hay que continuar la lucha porque los derechos que no se defienden todos los días acaban perdiéndose. (R2)

\section{Considerações Finais}

Segundo sugerem os resultados deste estudo, as mobilizações e ações de protesto, dentre elas as Mareas Blancas, alcançaram conquistas relevantes, conseguiram deter processos de privatização do setor saúde e possibilitaram retomar a concepção de universalidade no Sistema Nacional de Saúde da Espanha. No entanto, reminiscências do modelo anterior permanecem e persistem tensões e disputas com o setor privado. 
A ampliação das bases sociais de apoio aos sistemas universais de saúde parece ser um ponto central e merece ser objeto de maior profundidade, em novos estudos, especialmente sob um olhar direcionado aos/ às trabalhadores/as da área, pois a tendência da precarização das condições de trabalho influi diretamente no processo de lutas.

A renovação das forças de resistência e lutas dos indivíduos da sociedade pelo direito à saúde implica, sem dúvida, no enfrentamento das medidas neoliberais de austeridade. Porém exige, sobretudo, uma compreensão de que a luta é contra o capitalismo e sua inconformidade com o direito universal à saúde e com uma sociabilidade pautada na emancipação humana.

\section{Referências}

BERNAL-DELGADO, E. et al. España: Informe del sistema sanitario. Sistemas sanitarios en transición, Madri, v. 20, n. 2, p. 1-179, 2018. Disponível em: https://www.mscbs.gob.es/biblioPublic/publicaciones/recursos_propios/resp/pdf/REVISION_SISTEMA_ SANITARIO_ESPANOL_2018.pdf. Acesso em: 29 out. 2020.

BORGES, F. T.; LÓPEZ-FERNÁNDEZ, L. A. L.; CAMPOS, G. W. S. Políticas de austeridade fiscal: tentativa de desmantelamento do Sistema Nacional de Salud da Espanha e resistência cidadã. Saude soc., São Paulo, v. 27, n. 3, p. 715-728, set. 2018. Disponível em: http://www.scielo.br/scielo.php?script=sci_arttext\&pid=S010412902018000300715\&lng=pt\&nrm=iso. Acesso em: 22 out. 2020. CORDILHA, A. C.; LAVINAS, L. Transformações dos sistemas de saúde na era da financeirização. Lições da França e do Brasil. Ciênc. saúde coletiva, Rio de Janeiro, v. 23, n. 7, p. 2147-2158, jul. 2018. Disponível em: http://www.scielo.br/scielo.php?script=sci_ arttext\&pid=S1413-81232018000702147\&lng= pt\&nrm=iso. Acesso em: 22 out. 2020.

DURÁN, A.; LARA, J. L.; VAN WAVEREN, M. Spain: Health system review. Health Systems in Transition, Spain, v. 8, n. 4, p. 1-208, 2006. Disponível em: https://apps.who.int/iris/handle/10665/107796. Acesso em: 23 out. 2020.

ESPAÑA. [Gobierno]. Ley 14/1986, de 25 de abril, General de Sanidad. Boletín Oficial del Estado, n. 102, 29 abr. 1986, p. 1520715224. Disponível em: https://www.boe.es/eli/es/1/1986/04/25/14/con. Acesso em: 21 out. 2020.

ESPAÑA. [Gobierno]. Ley Orgánica 4/2015, de 30 de marzo, de protección de la seguridad ciudadana. Boletín Oficial del Estado, n. 77, de 31 mar. 2015. Disponível em: https://www.boe.es/eli/es/rdl/2012/04/20/16/con. Acesso em: 21 out. 2020.

ESPAÑA. [Gobierno]. Real Decreto-ley 16/2012, de 20 de abril, de medidas urgentes para garantizar la sostenibilidad del Sistema Nacional de Salud y mejorar la calidad y seguridad de sus prestaciones. Boletín Oficial del Estado, n. 98,24 abr. 2012. Disponível em: https://www.boe.es/eli/es/rdl/2012/04/20/16/con. Acesso em: 21 out. 2020.

ESPAÑA. [Gobierno]. Real Decreto-ley 7/2018, de 28 de julio, sobre el acceso universal ao Sistema Nacional de Salud. Boletín Oficial del Estado, núm. 183, 30 jul. 2018. Disponível em: https://www.boe.es/buscar/act.php?id=BOE-A-2018-10752\&p=20180730\&tn=1. Acesso em: 21 out. 2020 .

ESPING-ANDERSEN, G. As três economias políticas do welfare state. Lua Nova, São Paulo, n. 24, p. 85-116, set. 1991. Disponível em https://www.scielo.br/scielo.php?script=sci_arttext\&pid=S0102-64451991000200006\&lng=pt \&nrm=iso\&tlng=pt. Acesso em: 28 out. 2020.

GIOVANELLA, L.; STEGMULLER, K. Crise financeira europeia e sistemas de saúde: universalidade ameaçada? Tendências das reformas de saúde na Alemanha, Reino Unido e Espanha. Cad. Saúde Pública, Rio de Janeiro, v. 30, n. 11, p. 2263-2281, nov. 2014. Disponível em http://www.scielo.br/scielo.php?script=sci_arttext\&pid=S0102-311X2014001102263\&lng=pt\&nrm=iso. Acesso em: 23 out. 2020.

LÓPEZ-FERNÁNDEZ, L. A. et al. ¿Está en peligro la cobertura universal en nuestro Sistema Nacional de Salud? Gac Sanit, Barcelona, v. 26, n. 4, p. 298-300, ago. 2012. Disponível em: http://scielo.isciii.es/scielo.php?script=sci_arttext\&pid=S0213$91112012000400002 \& \operatorname{lng}=$ es \&nrm=iso. Acesso em: 23 out. 2020.

MATOS, A. R.; SABARIEGO, J. Movilización colectiva, transformación democrática y resistencia contra la crisis y la austeridad en el sur de Europa: la experiencia de Portugal y España. Revista Española De Sociología, v. 29, n. 1, p. 71-86, dez. 2019. Disponível em: https://recyt.fecyt.es/index.php/res/article/view/74262. Acesso em: 28 out. 2020.

MINAYO, M. C. S. O desafio do conhecimento: pesquisa qualitativa em saúde. São Paulo: Hucitec, 2010.

PADILLA, J. ¿A quién vamos a dejar morir? Sanidad pública, crisis y la importancia de lo político. España, Madri: Capitán Swing, 2019. RICO, A.; BLAKEY, E. El impacto de la crisis en sanidad: recortes estructurales asimétricos con altos costes diferidos. In: Fundación Encuentro, editor. Informe España 2012. Madrid: Fundación Encuentro, marzo 2011. p. 173-233. Disponível em: https://www.easp. es/crisis-salud/busqueda/resultados/item/1030-el-impacto-de-la-crisis-en-sanidad-recortes-estructurales-asimetricos-con-altos-costesdiferidos-en-informe-espana-2012. Acesso em: 23 out. 2020. 
RUIZ, S. F.; SÁNCHEZ BAYLE, M. España: Grandes retrocesos en el Sistema Sanitario con algunas expectativas de mejora. Tempus, actas de saúde colet., Brasília, v. 10, n. 1, p. 59-73, mar. 2016. Disponível em: http://www.tempusactas.unb.br/index.php/tempus/article/ view/ 1870/1592. Acesso em: 11 out. 2020.

SÁNCHEZ BAYLE, M.; RUIZ, S. F. Movilizaciones sociales y profesionales en España frente a la contrarreforma sanitaria. Saúde debate, Rio de Janeiro, v. 38, n. 103, p. 886-899, dez. 2014. Disponível em: http://www.scielo.br/scielo.php?script=sci_arttext\&pid=S0103$11042014000400886 \& \operatorname{lng}=$ pt\&nrm=iso. Acesso em: 28 out. 2020.

SERAPIONI, M. Crise econômica e desigualdades nos sistemas de saúde dos países do Sul da Europa. Cad. Saúde Pública, Rio de Janeiro, v. 33, n. 9, p. 1-14, 2017. Disponível em http://www.scielo.br/scielo.php?script=sci_arttext\&pid=S0102-311X2017000903001\&lng =pt\&nrm=iso. Acesso em: 22 out. 2020.

SPOSATI, A. Descaminhos da seguridade social e desproteção social no Brasil. Ciênc. saúde coletiva, Rio de Janeiro, v. 23, n. 7, p. 2315-2325, jul. 2018. Disponível em http://www.scielo.br/scielo.php?script=sci_arttext\&pid=S1413-81232018000702315\&lng $=$ pt\&nrm=iso. Acesso em: 28 out. 2020.

SUESS, A. et al. El derecho de acceso sanitario en el contexto del Real Decreto-ley 16/2012: la perspectiva de organizaciones de la sociedad civil y asociaciones profesionales". Gac Sanit, Barcelona, v. 28, n. 6, p. 461-469, dez. 2014.

\section{Andreia de Oliveira}

andreiaoliveirasus@gmail.com

Doutorado em Serviço Social pela Pontifícia Universidade Católica de São Paulo (PUC-SP)

Professora na graduação em Serviço Social e no Programa de Pós Graduação em Política Social na

Universidade de Brasília (UnB)

\section{UnB}

Campus Universitário Darcy Ribeiro - Asa Norte Brasília - Distrito Federal - Brasil.

CEP: $70.910-900$

\section{Jorge Marcos Marcos}

jorge.marcosmarcos@ua.es

Doctor en Antropología Social por la Universidad de Granada, España.

Docente e investigador del Departamento de Psicología de la Salud de la Universidad de Alicante, España.

\section{UA}

Campus de San Vicent del Raspeig Ap 99. E-03080, Alicante, España.

\section{Carlos Alvarez-Dardet Díaz}

carlosalvarezdardetdiaz@gmail.com

Licenciado y Doctor en Medicina per la Universidad de Sevilla, España. Catedrático de Medicina

Preventiva y Salud Pública en la Universidad de Alicante, España.

\section{UA}

Campus de San Vicent del Raspeig Ap 99. E-03080, Alicante, España.

\begin{abstract}
Agradecimentos
Sinceros agradecimentos a respeitosa acolhida do Grupo de Investigação em Saúde Pública da Faculdade de Ciências da Saúde da Universidade de Alicante, especialmente o professor Doutor Carlos Alvarez-Dardet Diaz, que com toda a generosidade acompanhou o estudo ao longo do
\end{abstract}

período. No mesmo sentido, registro meu reconhecimento aos respondentes chaves, sujeitos desta pesquisa, que se disponibilizaram a contribuir com o estudo. A Fundação de Apoio à Pesquisa do Distrito Federal -FAPDF, por ter financiado o estudo por meio do Programa de Bolsas de PósDoutorado no Exterior. 


\section{Agência financiadora}

$\mathrm{O}$ estudo foi financiado pela Fundação de Apoio à Pesquisa do Distrito Federal -FAPDF, no âmbito do Programa de Bolsas de Pós - Doutoramento no Exterior, Edital DPG/UnB No 05/2018. Contribuições das/os autoras/es

Todos os autores atendem aos critérios de autoria. Andreia de Oliveira concebeu, desenhou o estudo, coletou as informações, analisou os dados e redigiu o manuscrito. Jorge Marcos Marcos participou no desenho da pesquisa, na discussão dos resultados e na revisão do artigo. Carlos Alvarez-Dardet Diaz participou no desenho da pesquisa, na discussão dos resultados, na revisão do artigo e orientou todos os aspectos da sua condução. Os três autores aprovaram a versão final do texto.

Aprovação por Comitê de Ética e consentimento para participação

Os sujeitos da pesquisa assinaram "Formulario de información y consentimiento informado escrito".

Consentimento para publicação

Consentimento dos autores.

Conflito de interesses

Não há conflito de interesses. 